\title{
Induction of Potent Antitumor Immunity by Sustained Release of Cationic Antigen from a DNA-Based Hydrogel with Adjuvant Activity
}

\section{$\operatorname{AUTHOR}(S)$ :}

Umeki, Yuka; Mohri, Kohta; Kawasaki, Yohji;

Watanabe, Hiroshi; Takahashi, Rei; Takahashi, Yuki; Takakura, Yoshinobu; Nishikawa, Makiya

\section{CITATION:}

Umeki, Yuka ... [et al]. Induction of Potent Antitumor Immunity by Sustained Release of Cationic Antigen from a DNA-Based Hydrogel with Adjuvant Activity. Advanced Functional Materials 2015, 25(36): 5758-5767

\section{ISSUE DATE:}

2015-09

\section{URL:}

http://hdl.handle.net/2433/202594

\section{RIGHT:}

This is the peer reviewed version of the following article: Umeki, Y., Mohri, K., Kawasaki, Y., Watanabe, H., Takahashi, R., Takahashi, Y., Takakura, Y. and Nishikawa, M. (2015), Induction of Potent Antitumor Immunity by Sustained Release of Cationic Antigen from a DNA-Based Hydrogel with Adjuvant Activity. Adv. Funct. Mater., 25: 5758-5767, which has been published in final form at http://dx.doi.org/10.1002/adfm.201502139. This article may be used for non-commercial purposes in accordance with Wiley Terms and Conditions for Self-Archiving.; The full-text file will be made open to the public on 13 AUG 2016 in accordance with publisher's 'Terms and Conditions for Self-Archiving'.; This is not the published version. Please cite only the published version.; この論文は出版社版でありません。引用の際には出版社版 をご確認ご利用ください。 


\section{WILEY-VCH}

DOI: 10.1002/ ((please add manuscript number))

\section{Article type: Full Paper}

\section{Induction of Potent Antitumor Immunity by Sustained Release of Cationic Antigen from a DNA-based Hydrogel with Adjuvant Activity}

Yuka Umeki, Kohta Mohri, Yohji Kawasaki, Hiroshi Watanabe, Rei Takahashi, Yuki

Takahashi, Yoshinobu Takakura, and Makiya Nishikawa*

((Optional Dedication))

Y. Umeki, Dr. K. Mohri, Dr. Y. Takahashi, Dr. Y. Takakura, Dr. M. Nishikawa

Department of Biopharmaceutics and Drug Metabolism, Graduate School of Pharmaceutical Sciences, Kyoto University, Sakyo-ku, Kyoto 606-8501, Japan.

E-mail: makiya@pharm.kyoto-u.ac.jp

Y. Kawasaki, Dr. H. Watanabe

Institute for Chemical Research, Kyoto University, Gokasho, Uji, Kyoto 611-0011, Japan.

Dr. R. Takahashi

Department of Pharmacotherapeutics, Faculty of Pharmaceutical Sciences, Doshisha Women's College of Liberal Arts, Kyotanabe, Kyoto 610-0395, Japan.

Keywords: hydrogel, DNA, immune cell, controlled release, cationization

((maximum five, not capitalized, plural, separated by commas, no full stop))

((Abstract text. 12 point, double-spaced. Maximum length 200 words. Written in the present tense and impersonal style.)) 


\section{WILEY-VCH}

Our previous studies indicate that immunostimulatory DNA-based injectable hydrogels harboring unmethylated cytosine-phosphate-guanine (CpG) dinucleotides meet the requirements of an effective antigen delivery system, including safety, biodegradability, ease of administration, and stimulation of the innate immune system. However, rapid release of the model antigen ovalbumin (OVA) from the hydrogel limits its potential. Here it is aimed to achieve sustained OVA release from a DNA hydrogel through cationization of the antigen. Ethylenediamine (ED)-conjugated cationized OVA (ED-OVA), but not OVA, forms a complex with hexapod-like structured DNA, a component of the DNA hydrogel. The release of ED-OVA from the hydrogel is significantly slower than that of OVA. ED-OVA mixed with CpG DNA hydrogel efficiently binds to mouse dendritic DC2.4 cells and results in high antigen presentation. Intratumoral injections of ED-OVA/CpG DNA hydrogel significantly delays tumor growth of OVA-expressing EG7-OVA cells in mice. Then, a cationic OVA peptide antigen (R8-L2-pepI) consisting of an OVA MHC class I epitope, octaarginine, and a linker is designed. Intratumoral injections of R8-L2-pepI/CpG DNA hydrogel eradicate tumors in 5 out of 6 mice. Thus, it is concluded that a vaccine consisting of immunostimulatory CpG DNA hydrogel and cationized antigens can be effective for cancer immunotherapy.

\section{Introduction}

The elimination of cancer cells by activation of the immune system is a general underlying mechanism of not only cancer immunotherapy but also other modalities of cancer therapy, including radiotherapy and chemotherapy ${ }^{[1]}$. Vaccination with tumor-associated antigens induces antigen-specific immune responses that inhibit or even eradicate tumor growth in 


\section{WILEY-VCH}

preclinical and clinical settings ${ }^{[2]}$. Recent studies demonstrated that adjuvants stimulating innate immunity are required to elicit potent adaptive immunity ${ }^{[3]}$. In addition, antigen delivery systems should possess the ability to continuously deliver tumor antigens to antigen presenting cells (APCs) as well as stimulate innate immunity ${ }^{[3]}$. They are also required to be safe, simple, chemically synthesizable, biocompatible, and biodegradable ${ }^{[4]}$. Today, various antigen delivery systems based on synthetic hydrogels and nanoparticles are reported ${ }^{[5-7]}$.

One of the most well studied adjuvants is DNA containing unmethylated cytosinephosphate-guanine (CpG) dinucleotides (CpG DNA) ${ }^{[8-10]}$, which is recognized by Toll-like receptor 9 (TLR9) expressed by mammalian immune cells ${ }^{[11]}$. CpG DNA induces the release of T helper type I cytokines from TLR9-positive cells. There are several classes of CpG DNAs, the linkages of which are partially or fully phosphorothioated ${ }^{[12,13]}$. Therapeutic applications of CpG DNA in chronic viral infection and cancer have been tested ${ }^{[14]}$. In its application as an adjuvant for cancer immunotherapy, CpG DNAs are generally administered with tumor-associated antigens, but little attention has been paid to the pharmacokinetics of the adjuvants. In addition, phosphorothioated DNA increases non-specific binding to proteins, which could lead to nephrotoxicity ${ }^{[15]}$. Therefore, enzymatically stable forms of phosphodiester CpG DNA can be an alternative to phosphorothioate modification as safer CpG DNA adjuvants ${ }^{[16,17]}$.

Our studies on polypod-like structured DNA, or polypodna, which is a DNA assembly consisting of three or more oligodeoxynucleotides (ODNs), showed that such complicated structured DNAs serve as highly efficient delivery systems of CpG DNA to TLR9-positive immune cells ${ }^{[18-20]}$. Recently, we developed a ligase-free procedure for preparing DNA hydrogel, and found that this ligase-free DNA hydrogel is an injectable formulation that can encapsulate ovalbumin (OVA) by simple mixing of the DNA units of the 


\section{WILEY-VCH}

hydrogel and OVA ${ }^{[21]}$. We demonstrated that the CpG DNA-containing DNA hydrogel (CpG DNA hydrogel) encapsulating OVA was effective in inducing potent OVA-specific immune responses with less toxicity than complete Freund's adjuvant (CFA) or alum, a clinically available vaccine adjuvant ${ }^{[21]}$. However, OVA was released from the hydrogel with a half-life of about $2.5 \mathrm{~h}$, and this rapid release reduced the potency of the injectable CpG DNA hydrogel as a controlled antigen delivery system with adjuvant activity.

Sustained release of antigen would increase antigen-specific immune responses ${ }^{[22]}$. Negatively charged OVA (isoelectric point of 4.5-4.8) hardly interacts with DNA, but its cationized derivatives would electrostatically interact. Based on these considerations, we aimed to achieve controlled release of the OVA antigen from DNA hydrogel by using positively charged antigens. Here we show that cationized OVA is slowly released from CpG DNA hydrogel, and intratumoral injections of this formulation is more potent than noncationized OVA/DNA hydrogel in suppressing the growth of EG7-OVA tumors in mice. Considering that antigen peptides have advantages over cationized antigen proteins in terms of product quality, purity, and productivity, we have also designed a cationic OVA peptide antigen (R8-L2-pepI) and demonstrated that injections of R8-L2-pepI/DNA hydrogel efficiently eradicated EG7-OVA tumors.

\section{Results}

2.1. Cationized OVA formed a complex with DNA and was gradually released from DNA hydrogel. 


\section{WILEY-VCH}

Table 1. Characteristic of ED-OVA derivatives. OVA was modified with ED using EDAC. The degree of cationization was assessed by estimating the additional amino groups as measured by TNBS.

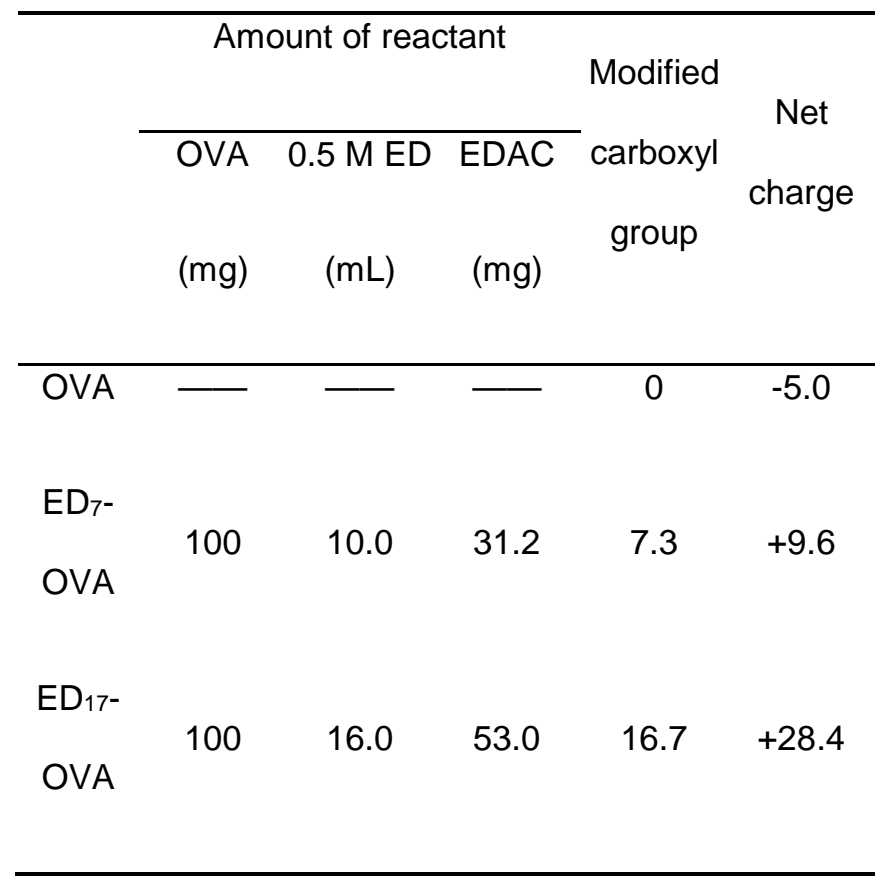

Table 1 summarizes the number of modified carboxyl groups and the net charge of ethylenediamine (ED)-conjugated OVAs (ED-OVAs). The average number of modified carboxyl groups was 7.3 and 16.7 for $\mathrm{ED}_{7}-\mathrm{OVA}$ and ED $17-\mathrm{OVA}$, respectively. The net charge, estimated from the amino acid composition and the degree of modification, was positive for both ED-OVA derivatives. Covalently conjugated oligomers or aggregates of OVA, which could be formed through the covalent bonding among ED-OVA molecules, were scarcely found in the ED-OVA samples, as assessed by sodium dodecyl sulfate-polyacrylamide gel electrophoresis (SDS-PAGE) (Figure S1). 


\section{WILEY-VCH}
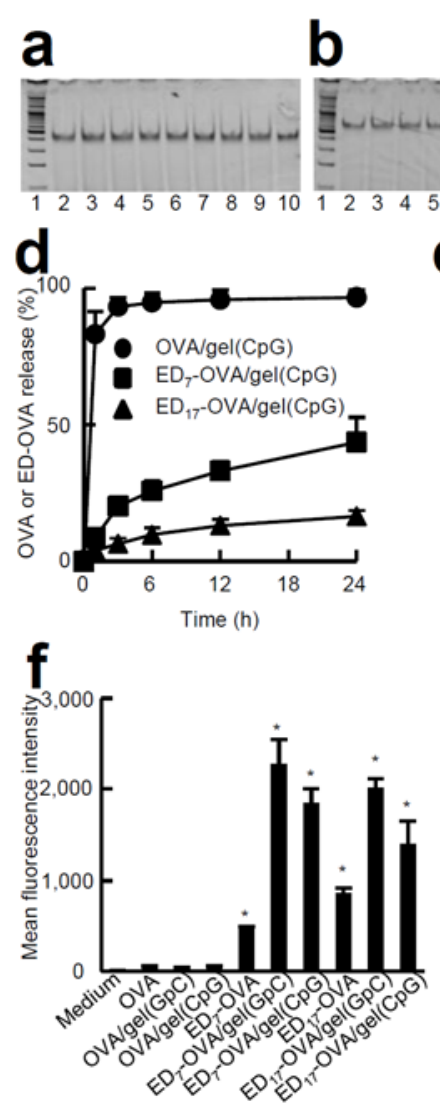

\section{e}
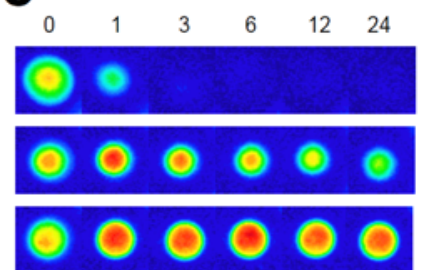
1024

3063

$g_{20}$

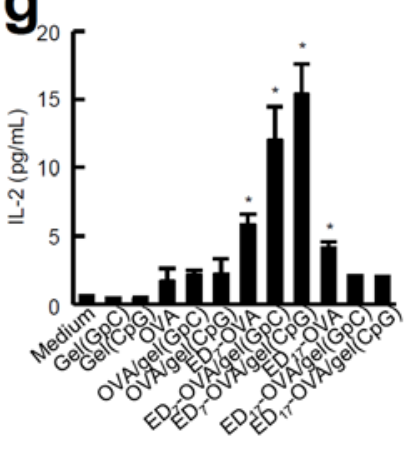

Figure 1. Properties of OVA

and ED-OVAs mixed with hexapodna or incorporated into DNA hydrogel. (a) OVA, (b) ED $7-O V A$, or (c) $\mathrm{ED}_{17-\mathrm{OVA}}$ was incubated with hexapodna at different mixing ratios for $15 \mathrm{~min}$ at $37^{\circ} \mathrm{C}$. The mixture was then subjected to electrophoresis using a $6 \%$ polyacrylamide gel at $200 \mathrm{~V}$ for $20 \mathrm{~min}$, and DNA was detected with ethidium bromide. The molar ratios of $\mathrm{GpC}$ hexapodna and

OVA or ED-OVAs were 1:0 (lane 2), 1:0.1 (lane 3), 1:0.2 (lane 4), 1:0.4 (lane 5), 1:1 (lane 6), 1:5 (lane 7), 1:10 (lane 8), 1:50 (lane 9), and 1:100 (lane 10). The 100 bp DNA ladder is shown in lane 1 (Watson, Tokyo, Japan). (d) FITC-OVA or FITC-ED-OVAs (10 $\mu$ g) were incorporated into $100 \mu \mathrm{g}$ of CpG DNA hydrogel, and the product was placed into the upper chamber of the Transwell ( $0.4 \mu \mathrm{m}$ pore size) with the bottom chamber containing phosphate buffered saline (PBS), and incubated at $37^{\circ} \mathrm{C}$. The fluorescence intensity of the solution in the bottom chamber was measured, and the percentages of OVA or ED-OVAs released were calculated and plotted against time. Results are expressed as the mean \pm S.D. of four independent samples. Results are typical of three separate experiments with similar results. (e) The fluorescent images of the hydrogel in the upper chamber were photographed at the indicated times: (upper) OVA, (middle) ED7-OVA, and (lower) ED ${ }_{17}-\mathrm{OVA}$. (f) DC2.4 cells 


\section{WILEY-VCH}

were incubated with $500 \mu \mathrm{g} / \mathrm{ml}$ FITC-OVA or FITC-ED-OVAs in the presence or absence of $10 \mu \mathrm{g} / \mathrm{ml}$ CpG DNA hydrogel. The amounts of FITC-OVA or FITC-ED-OVAs associated with the cells were measured by flow cytometry. Results are expressed as mean \pm S.D. of four independent samples. Results are typical of four separate experiments with similar results. ${ }^{*} P<0.05$ compared with the medium group. (g) DC2.4 cells were plated on 96-well culture plates at a density of $5 \times 10^{4}$ cells/well and incubated overnight. DNA $(10 \mu \mathrm{g} / \mathrm{ml})$ and OVA or ED-OVAs $(500 \mu \mathrm{g} / \mathrm{ml})$ were added to each well, and then $5 \times 10^{4}$ CD8OVA1.3 cells were added and incubated at $37^{\circ} \mathrm{C}$ in $5 \% \mathrm{CO}_{2}$ for an additional $24 \mathrm{~h}$. The IL-2 concentration in culture media was measured by ELISA. Results are expressed as mean \pm S.D. of four independent samples. Results are typical of four separate experiments with similar results. $* P<0.05$ compared with the medium group.

Two sets of hexapod-like structured DNA (hexapodna) containing CpG DNA were designed, and an injectable DNA hydrogel was prepared by mixing as reported ${ }^{[21]}$. GpC DNA hydrogel was prepared by replacing CpG sequences in the ODNs of the CpG DNA hydrogel with GpC sequences, and was used as a control. Complex formation of OVA or ED-OVAs with DNA was examined by PAGE. Hexapodna containing GpC dinucleotide (GpC hexapodna-1) was used as model DNA. The migration of GpC hexapodna-1 slowed with increased addition of ED7-OVA or ED $17-O V A$ (Figure 1a-c). By contrast, the addition of OVA had little impact on the migration of GpC hexapodna-1. Mixing ED-OVAs with GpC hexapodna-1 increased the apparent size of the samples, as measured by the dynamic light scattering method (Figure S2). Moreover, there was no significant difference in the apparent 


\section{WILEY-VCH}

size of OVA and ED-OVAs, which indicates that aggregates were hardly formed in the cationization reaction.

Figure 1d shows a time course of the fluorescence intensity of the bottom chamber of the Transwell plate after addition of CpG DNA hydrogel containing fluorescein isothiocyanate (FITC)-labeled OVA, FITC-ED 7 -OVA or FITC-ED $17-O V A$ onto the insert. FITC-OVA was released from the DNA hydrogel with a half-life of less than $1 \mathrm{~h}$, whereas the release of FITCED-OVAs was much slower; with FITC-ED ${ }_{17}-O V A$ demonstrating the slowest release rate. The slow release of FITC-ED-OVAs from the DNA hydrogel compared with FITC-OVA was confirmed by fluorescent images (Figure 1e). The released samples were collected $3 \mathrm{~h}$ after incubation and PAGE analysis was performed to detect the OVA protein as well as DNA (Figure S3a - c). The bands of OVA and ED-OVAs were smear because the gel was run under non-reducing conditions. Segments of OVA and DNA migrated to the same position in the polyacrylamide gel, suggesting that ED-OVAs are released in the complex form with DNA. The release of FITC-ED-OVAs from DNA hydrogel was accelerated in the presence of fetal bovine serum (FBS) (Figure S3d). The viscoelastic property of the DNA hydrogel was examined by measuring the storage modulus using a rheometer. No significant changes were observed in the storage modulus by the encapsulation of OVA or ED 7 -OVA into the hydrogel (Figure S4).

\subsection{Cellular uptake and MHC class I presentation of ED-OVA was increased by combination with DNA.}

Cellular uptake of FITC-OVA and FITC-ED-OVAs was examined in mouse dendritic DC2.4 cells. Figure $1 \mathrm{~F}$ shows the mean fluorescence intensity (MFI) of DC2.4 cells after 2 h- 


\section{WILEY-VCH}

incubation with FITC-OVA or FITC-ED-OVAs in the presence or absence of CpG or GpC DNA hydrogel. The MFI of the cells treated with FITC-ED-OVAs was higher than that of cells treated with FITC-OVA, which could be due to the electrostatic interaction of ED-OVAs with the negatively charged cell surface. The addition of CpG DNA hydrogel significantly increased the cellular uptake of FITC-ED-OVAs, whereas only a slight increase was observed when the hydrogel was added to FITC-OVA. Similar results were obtained when the GpC DNA hydrogel was used instead of the CpG DNA hydrogel.

MHC class I-restricted cross-presentation of OVA was measured using CD8OVA1.3 T hybridoma cells that release IL-2 upon stimulation with a complex of the SIINFEKL $\left(\mathrm{OVA}_{257-264}\right)$ peptide and $\mathrm{K}^{\mathrm{b}}$ (Figure $\left.1 \mathrm{~g}\right)$. Low IL-2 production was observed when CD8OVA1.3 T hybridoma cells interacted with OVA. In contrast, the addition of either ED $_{7-}$ OVA or ED $17-O V A$ resulted in higher amounts of IL-2 secretion. ED7-OVA was more potent than ED $17-O V A$ in inducing IL-2 secretion, which correlates with our previous report ${ }^{[23]}$. Furthermore, addition of CpG or GpC DNA hydrogel to ED7-OVA significantly increased IL2 production.

\subsection{ED-OVA/CpG DNA hydrogel induced strong OVA-specific immune responses in mice.}

As a result of its capacity to generate relatively higher IL-2 production upon interaction with CD8OVA1.3 T hybridoma cells, ED 7 -OVA was selected and used as the cationized OVA antigen in the following experiments. Figure 2a shows time course analyses of fluorescence intensity in mouse skin after intradermal injection of FITC-OVA or FITC-ED7-OVA at a dose of $10 \mu \mathrm{g}$ in the presence or absence of CpG DNA hydrogel. The fluorescence intensity rapidly decreased from the injection site after injection of FITC-OVA, and the rate of decrease was 


\section{WILEY-VCH}

not significantly affected by co-injection with CpG DNA hydrogel. However, in mice receiving ED7-OVA, a slow decrease in fluorescence intensity was observed. Furthermore, the decrease was significantly delayed by the incorporation of FITC-ED $7-O V A$ into CpG DNA hydrogel, which indicates that antigen release from DNA hydrogel is prolonged by use of cationized antigen.

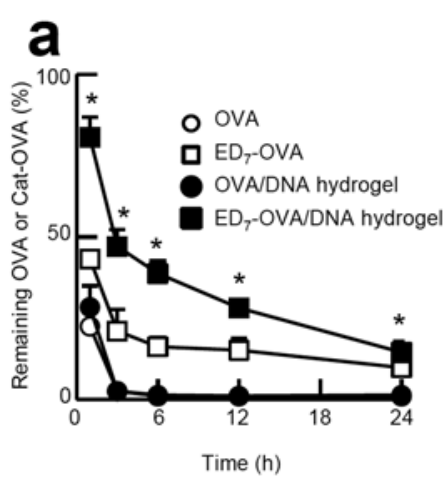

\section{b}

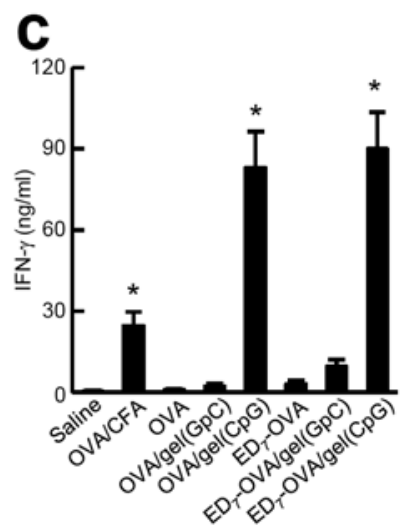

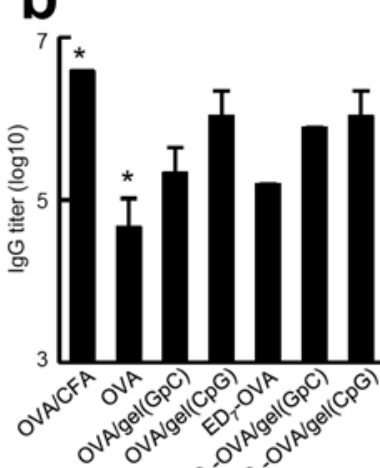

d

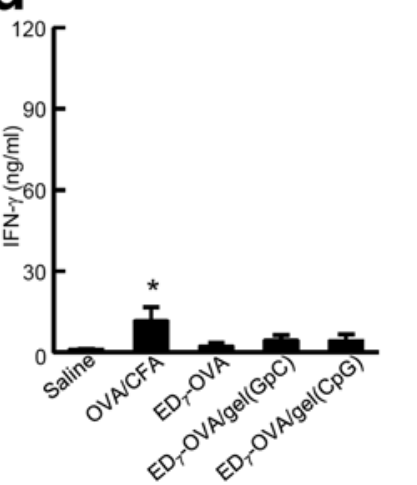

Figure 2. Disappearance of OVA or ED7-OVA from the injection site and induction of OVA-specific immune responses after intradermal injection of OVA or $\mathrm{ED}_{7}-\mathrm{OVA}$ into mice. (a) ICR mice were intradermally injected with $10 \mu \mathrm{g}$ FITC-OVA or FITC-ED 7 -OVA in the presence or absence of $100 \mu \mathrm{g} \mathrm{CpG}$ DNA hydrogel $(10 \mu 1 /$ shot $)$. At the indicated times after injection, mice were anesthetized and the skin tissues including the injection site were excised and homogenized. The fluorescence intensity of the supernatant of the homogenates was then measured. Results are expressed as mean \pm S.D. of four mice. Results are typical of two separate experiments with similar results. ${ }^{*} P<0.05$ compared with the other groups. (b) C57BL/6 mice were immunized with OVA or ED7-OVA with or without DNA by three intradermal injections at weekly intervals. On day 7 post the last immunization, OVA-specific total IgG levels in serum were measured by ELISA. Serum total IgG titers were estimated by 


\section{WILEY-VCH}

the dilution ratio at which the absorbance value of the saline group was obtained. Results are expressed as mean \pm S.D. of four mice (saline-, CFA-, and OVA-treated groups) or five mice (other groups). Results are typical of two separate experiments with similar results. ${ }^{*} P<0.05$ compared with the other groups. (c) On day 7 post the last immunization, splenocytes were collected, stimulated with OVA (1 mg/ml), and incubated for 4 days. The IFN- $\gamma$ concentration in culture media was measured by ELISA. Results are expressed as mean \pm S.D. of four mice (saline-, CFA-, and OVA-treated groups) or five mice (other groups). Results are typical of two separate experiments with similar results. ${ }^{*} P<0.05$ compared with the saline group. (d) TLR9 knockout mice were immunized with OVA or ED 7 -OVA with or without DNA by three intradermal injections at weekly intervals. On day 7 post the last immunization, splenocytes were collected, stimulated with OVA $(1 \mathrm{mg} / \mathrm{ml})$, and incubated for 4 days. The IFN- $\gamma$ concentration in culture media was measured by ELISA. Results are expressed as mean \pm S.D. of five mice. Results are typical of two separate experiments with similar results. ${ }^{*} P<0.05$ compared with the other groups. 


\section{WILEY-VCH}

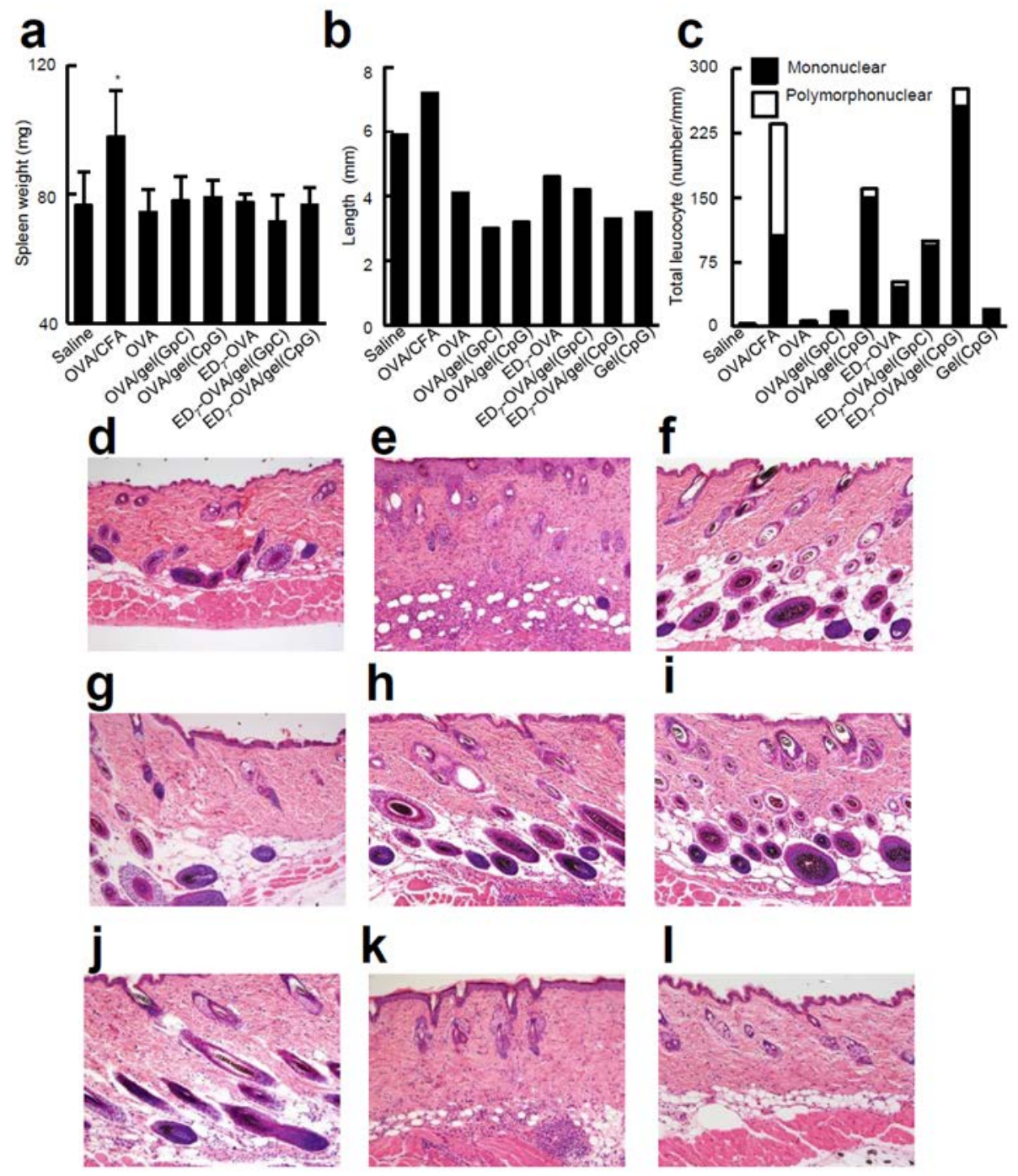

Figure 3. Systemic and local adverse reactions after intradermal injection of OVA or ED7OVA into mice. (a) Spleens were collected from C57BL/6 mice on day seven after the third immunization at weekly intervals. Spleen weight was measured and large spleens indicated splenomegaly. Results are expressed as mean \pm S.D. of five mice. ${ }^{*} P<0.05$ compared with the other groups. (b) Dermis length on day seven after the third immunization. (c) The number of leucocytes per length of dermis (number/mm). (d-l) Hematoxylin and eosin staining of the skin sections. (d) saline, (e) OVA/CFA, (f) OVA, (g) OVA/gel(GpC), (h) OVA/gel(CpG), (i)
ED 7 -OVA,
(j) ED7-OVA/gel(GpC),

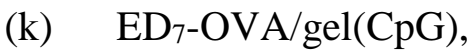
(l) $\operatorname{Gel}(\mathrm{CpG})$. 


\section{WILEY-VCH}

Figure $\mathbf{2 b}$ shows the OVA-specific total IgG antibody response in mice after immunization with OVA or ED7-OVA in the presence or absence of DNA hydrogel. Mice immunized with ED7-OVA showed higher IgG antibody levels than those immunized with OVA. Immunization of mice with $\mathrm{ED}_{7}-\mathrm{OVA} / \mathrm{CpG}$ DNA hydrogel was more potent than immunization with ED7-OVA alone. GpC DNA hydrogel was less effective than CpG DNA hydrogel when co-injected with ED 7 -OVA. Figure 2c shows the IFN- $\gamma$ production from splenocytes after re-stimulation with OVA, which is an indicator of the positive antigen specific responses. The $\mathrm{ED}_{7}-\mathrm{OVA}$-treated group showed higher IFN- $\gamma$ production than the OVA-treated group. The splenocytes of mice immunized with ED $-\mathrm{OVA} / \mathrm{CpG}$ DNA hydrogel produced higher amounts of IFN- $\gamma$ than the cells immunized with $\mathrm{ED}_{7}-\mathrm{OVA}$ alone or OVA/CpG DNA hydrogel. In the case of TLR9 knockout mice, IFN- $\gamma$ production was not increased by incorporation into CpG DNA hydrogel (Figure 2d). ED7-OVA mixed with CpG hexapodna (equimolar mixture of $\mathrm{CpG}$ hexapodna-1 and $\mathrm{CpG}$ hexapodna-3) was less effective than OVA incorporated into DNA hydrogel in inducing OVA-specific immune responses (Figure S5). The spleen weight of mice was significantly increased by immunization with OVA emulsified in CFA (Figure 3a), indicating this formulation developed splenomegaly, an undesirable adverse reaction of vaccination. No significant increase in spleen weight was observed in other groups, including the ED 7 -OVA/CpG DNA hydrogel-treated group. Infiltration of leucocytes at the injection site was also evaluated (Figure 3b-l). Despite comparable number of leukocytes being detected at the injection sites of ED7-OVA/CpG DNA hydrogel and OVA/CFA, the proportion of polymorphonuclear leukocytes, which increases in the acute phase of inflammation, was lower in the ED7- 


\section{WILEY-VCH}

OVA/CpG DNA hydrogel-treated group than in the OVA/CFA-treated group. This suggests that ED $_{7}-\mathrm{OVA} / \mathrm{CpG}$ DNA hydrogel induced only slight acute inflammation, which was apparent in OVA/CFA-treated mice.

\subsection{Intratumoral injection of ED 7 -OVA/CpG DNA hydrogel delayed EG7-OVA tumor} growth in mice. 
a

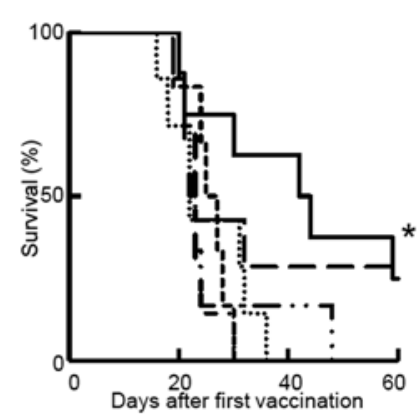

$$
\text { ........ saline -..- Gel(CpG) }
$$

-... $\mathrm{ED}_{T}$ OVA - OVAVgel(CpG)

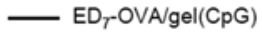

- $\cdots \mathrm{ED}_{T}$ OVA/gel(GpC)

C

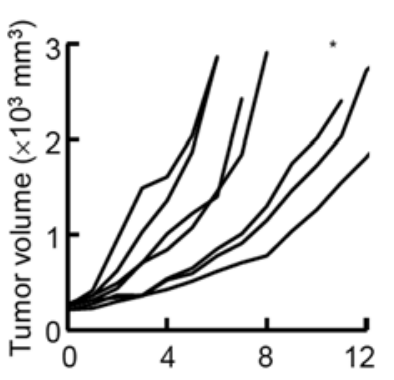

Days after first vaccination

f

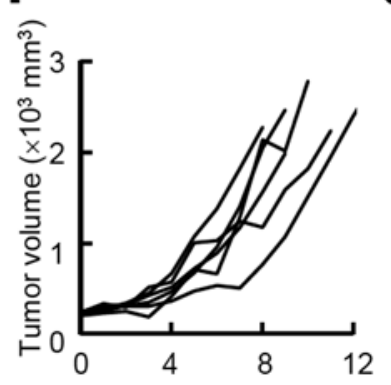

Days after first vaccination b

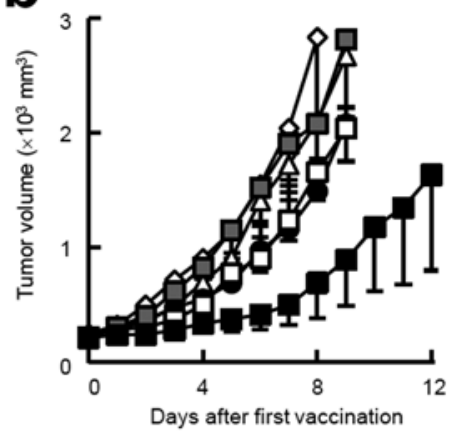

○ saline $\Delta \mathrm{Gel}(\mathrm{CpG}) \mathbf{\square} \mathrm{ED}_{T}$-OVA

- OVA/gel(CpG) $\mathrm{ED}_{T}$-OVA/gel(CpG)

口 $\mathrm{ED}_{T}$-OVAVgel(GpC)

\section{WILEY-VCH}
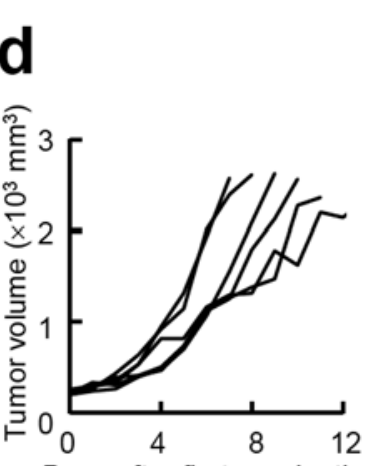

Days after first vaccination

g

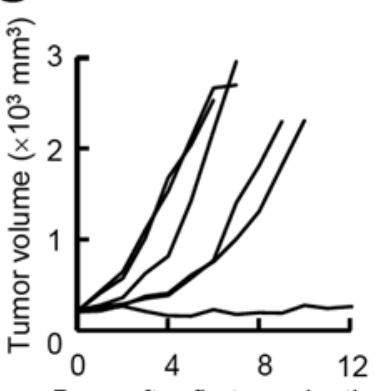

Days after first vaccination

\section{e}

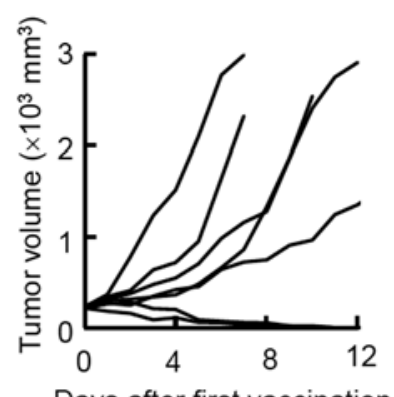

Days after first vaccination

h

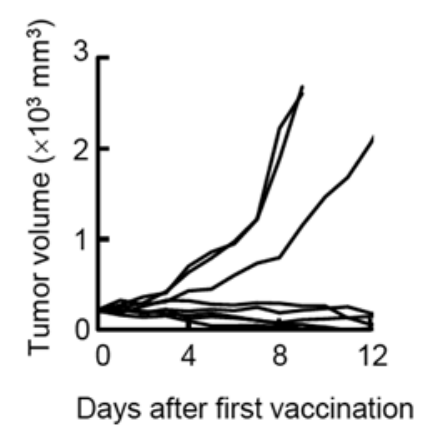

Figure 4. EG7-OVA tumor growth after intratumoral injection of ED $7-O V A / C p G$ DNA hydrogel into mice. EG7-OVA cells $\left(5 \times 10^{6}\right.$ cells) were intradermally inoculated into C57BL/6 mice. (a and b) When tumor volumes reached $>200 \mathrm{~mm}^{3}$, OVA or ED $7-O V A$ (10 $\mu \mathrm{g})$ and DNA hydrogel $(100 \mu \mathrm{g})$ were intratumorally injected three times at five-day intervals. Survival (a) and tumor size (b) were measured every day. Results are expressed as mean \pm 


\section{WILEY-VCH}

S.E.M. of six mice (Gel (CpG)-, ED $7-O V A-$, and ED7-OVA/gel (GpC)-treated groups), seven mice (saline-, and OVA/gel (CpG)-treated groups) or eight mice (ED7-OVA/gel (CpG)treated group). Results are typical of two separate experiments with similar results. ${ }^{*} P<0.05$ compared with the saline group. (c-h) Tumor volume of individual animals treated with the following agents was plotted: (c) saline, (d) Gel (CpG), (e) OVA/gel(CpG), (f) ED7-OVA, (g) ED 7 -OVA/gel(GpC), (h) ED 7 -OVA/gel(CpG). Results are typical of two separate experiments with similar results.

The anti-tumor effect of ED7-OVA/CpG DNA hydrogel was examined in EG7-OVA tumorbearing mice by intratumoral injection. Figure 4 shows the survival (a) and tumor size (b) of the tumor-bearing mice. ED $7-\mathrm{OVA} / \mathrm{CpG}$ DNA hydrogel was the most potent treatment, significantly inhibiting the growth of EG7-OVA tumors and inducing complete tumor regression in 2 out of 8 mice (Figure 4c-h). OVA/CpG DNA hydrogel and ED 7 -OVA/GpC DNA hydrogel also delayed tumor growth but were much less effective than ED $-\mathrm{OVA} / \mathrm{CpG}$ DNA hydrogel. In order to examine the induction of antigen-specific immunity, the mice that rejected EG7-OVA tumor with ED7-OVA/CpG DNA hydrogel treatment were rechallenged with EG7-OVA cells and mouse melanoma B16-B16 cells 2 months after the first tumor inoculation. The mice rejected growth of EG7-OVA cells upon rechallenge, but did not reject B16-BL6 cells (Table S1), which indicates that antigens incorporated into CpG DNA hydrogel induce long term antigen specific immunity.

\subsection{Cationic antigen peptide encapsulated into CpG DNA hydrogel showed remarkable therapeutic effects against the EG7-OVA tumor.}



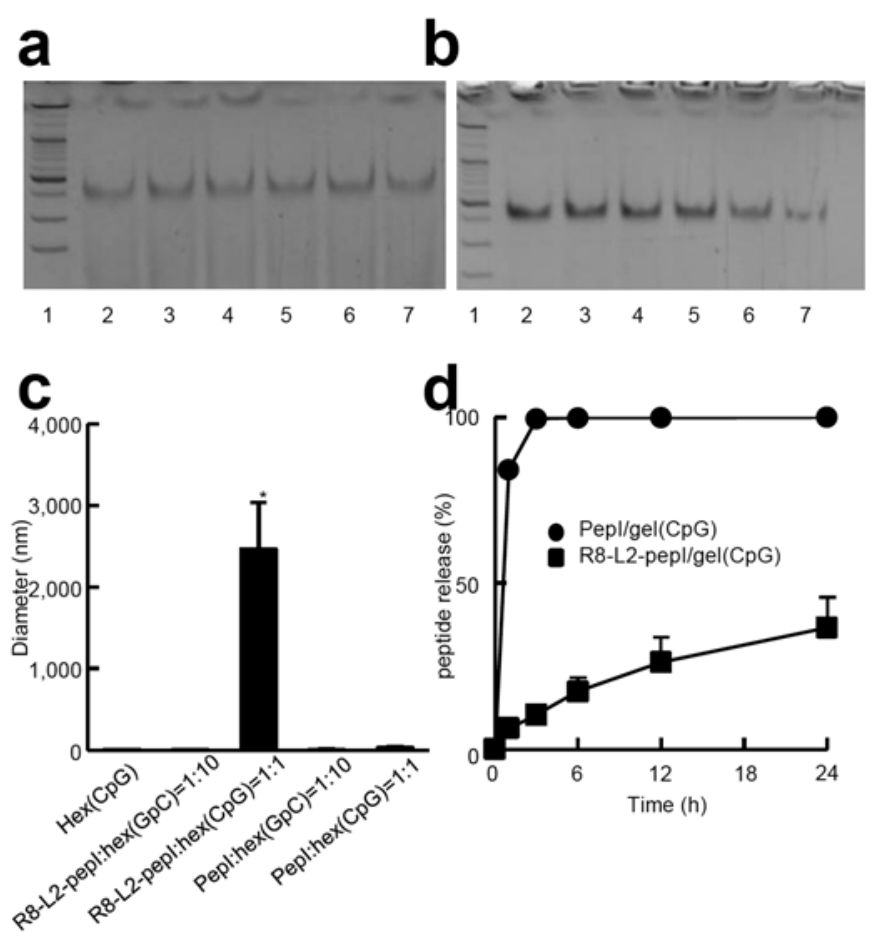

Figure 5. Complex formation of hexapodna and peptides and peptide release from DNA hydrogel. (a) pepI or (b) R8-L2-pepI was incubated with hexapodna at different mixing ratios for $15 \mathrm{~min}$ at $37^{\circ} \mathrm{C}$. The mixture was subjected to electrophoresis using a $6 \%$ polyacrylamide gel at $200 \mathrm{~V}$ for $20 \mathrm{~min}$ and DNA was detected with ethidium bromide. The molar ratios of CpG hexapodna and pepI or R8-L2-pepI were 1:0 (lane 2), 1:0.1 (lane 3), 1:1 (lane 4), 1:10 (lane 5), 1:50 (lane 6), 1:100 (lane 7). The 100 bp DNA ladder is shown in lane 1. (c) 0.1 $\mathrm{mg} / \mathrm{ml}$ pepI or R8-L2-pepI, and CpG hexapodna-1 was prepared using saline and mixed at various proportions. The size was then measured by DLS and expressed as the mean \pm S.D. of twenty independent measurements. ${ }^{*} P<0.05$ compared with the other groups. (d) FITC-pepI (3.45 $\mu \mathrm{g})$ or FITC-R8-L2-pepI $(10 \mu \mathrm{g})$ was incorporated into $100 \mu \mathrm{g}$ of CpG DNA hydrogel, and the product was placed into the upper chamber of the Transwell $(0.4 \mu \mathrm{m}$ pore size) with the bottom chamber containing PBS, and incubated at $37^{\circ} \mathrm{C}$. The fluorescence intensity of the solution in the bottom chamber was measured, and the percentages of pepI or R8-L2-pepI 


\section{WILEY-VCH}

released were calculated and plotted against time. Results are expressed as the mean \pm S.D. of four independent samples. Results are typical of two separate experiments with similar results.

Peptide antigens are more frequently used in clinical practice and research than protein antigens. Therefore, the results obtained with ED-OVA were extended to a peptide antigen. The OVA MHC class I epitope, SIINFEKL (pepI), was selected as a model peptide antigen. Next, a cationic peptide antigen (R8-L2-pepI) was designed by linking octaarginine (R8) to the N-terminal of pepI through a FFRK linker (L2), which is reportedly cleaved by both lysosomal and non-lysosomal pathways ${ }^{[24]}$. The DNA band on PAGE analysis became weaker with increasing amounts of R8-L2-pepI (Figure 5a, b), indicating that R8-L2-pepI formed a complex with CpG hexapodna-1. The apparent size of the mixture of CpG hexapodna-1 and R8-L2-pepI was significantly larger than CpG hexapodna-1 alone (Fig. 5c). The release of FITC-R8-L2-pepI from CpG DNA hydrogel was much slower than that of FITC-pepI (Figure 5d). Intratumoral injections of R8-L2-pepI/CpG DNA hydrogel effectively increased the survival of tumor-bearing mice (Figure 6a) and inhibited the growth of EG7OVA tumors (Figure 6b). The EG7-OVA tumor completely regressed in 5 out of 6 mice treated with R8-L2-pepI/CpG DNA hydrogel (Figure 6c-i). Furthermore, mice that were treated with R8-L2-pepI/CpG DNA hydrogel rejected EG7-OVA cells, but not B16-BL6 cells (Table S2), indicating the generation of tumor specific immunity. 


\section{WILEY-VCH}

a
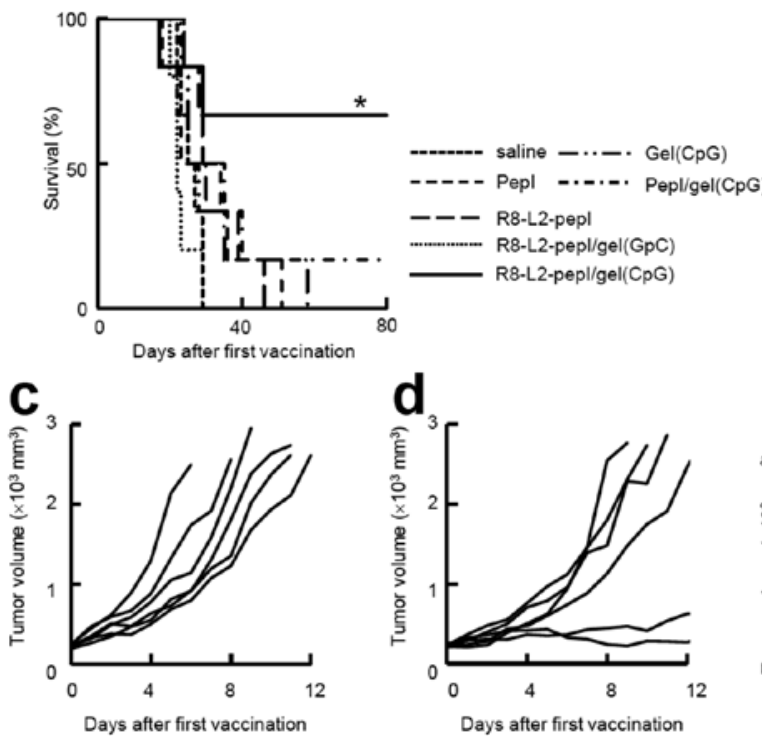

g
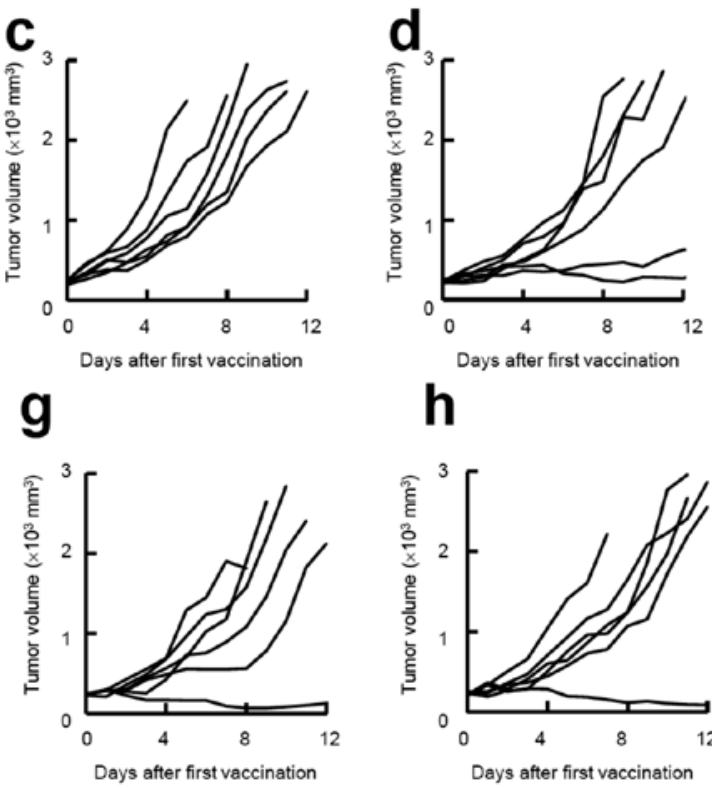

h b
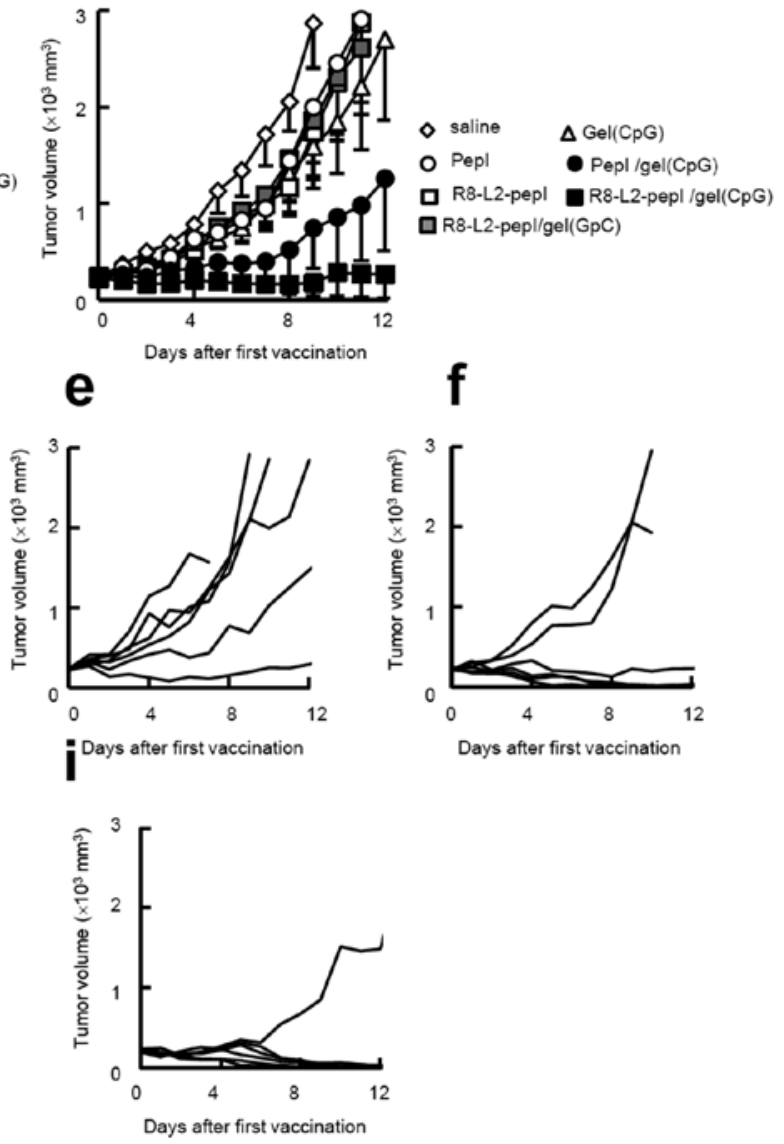

Figure 6. EG7-OVA tumor growth after intratumoral injection of R8-L2-pepI/CpG DNA hydrogel into mice. EG7-OVA cells $\left(5 \times 10^{6}\right.$ cells) were intradermally inoculated into C57BL/6 mice. (a and b) When tumor volumes reached $>200 \mathrm{~mm}^{3}$, pepI (3.45 $\mu \mathrm{g}$ ) or R8-L2pepI $(10 \mu \mathrm{g})$ and DNA hydrogel $(100 \mu \mathrm{g})$ were intratumorally injected three times at five-day intervals. Survival (a) and tumor sizes (b) were measured every day. Results are expressed as mean \pm S.E.M. of six mice. Results are typical of two separate experiments with similar results. ${ }^{*} P<0.05$ compared with the saline group. (c-h) Tumor volume of individual animals treated with the following agents was plotted: (c) saline, (d) Gel (CpG), (e) pepI, (f) 


\section{WILEY-VCH}

pepI/gel(GpC), (g) R8-L2-pepI, (h) R8-L2-pepI/gel(GpC), (i) R8-L2-pepI/gel(CpG). Results are typical of two separate experiments with similar results.

\section{Discussion}

Adjuvants are an essential component of vaccines used to efficiently elicit desirable immune responses ${ }^{[3]}$. Currently, insoluble aluminum salts, which were identified in the 1920 s $^{[25]}$, are widely used in licensed vaccines ${ }^{[26]}$. However, due to safety concerns and the origin of the materials, there are very few licensed vaccine adjuvants that are approved for human use ${ }^{[4]}$. Generally, vaccine adjuvants need to be safe, simple, biodegradable, and synthetic for clinical application ${ }^{[26]}$. DNA hydrogel, which contains immunostimulatory CpG motifs, meets these requirements. One possible drawback of the injectable DNA hydrogel system that we developed could be the rapid release of antigens from the hydrogel ${ }^{[21]}$. In the present study, we however demonstrated that antigen release from DNA hydrogel can be prolonged by cationization of the antigen, and the combination of DNA hydrogel and cationized antigen efficiently induces antigen-specific tumor immunity.

Drug release from hydrogels is mainly understood by diffusion-controlled mechanisms, and drug release rates are dependent on the diffusion coefficient ${ }^{[27]}$. Decreasing the diffusion coefficient leads to slow drug release from hydrogels. The diffusion coefficient is decreased by the reduction of mesh size or enhancement of the interaction between drugs and the gel matrix ${ }^{[28]}$. Concerning antigen release from negatively charged DNA hydrogel, the diffusion coefficient of antigens can be decreased by use of cationized antigens. DNA hydrogel will retain cationized antigens by electrostatic interaction, and the dissociation of the DNA components from the hydrogel will accelerate their release. This hypothesis is supported by 


\section{WILEY-VCH}

the accelerated ED-OVA release from DNA hydrogel by DNase-containing FBS; DNase promotes the enzymatic degradation of the hydrogel, and this degradation then accelerates the release of ED-OVAs. This hypothesis is supported by the accelerated ED-OVA release from DNA hydrogel by DNase-containing FBS; DNase promotes the enzymatic degradation of the hydrogel, and this degradation then accelerates the release of ED-OVAs. The superior results of ED7-OVA/GpC DNA hydrogel over $\mathrm{ED}_{7}-\mathrm{OVA}$ alone (Figure 2b, c) indicate that the controlled release of OVA is important for the induction of OVA-specific immune responses, because GpC DNA hydrogel functions as a non-immunostimulatory, bioinert delivery system. Conversely, ED7-OVA mixed with CpG hexapodna was less effective than OVA/CpG DNA hydrogel in inducing OVA-specific immune responses (Figure S5), indicating the importance of controlled release of antigens for potent antitumor immunity. Taken together, these results indicate that both gradual release of antigen and the immune potentiating activity of CpG DNA hydrogel are important for the induction of antigen-specific tumor immunity (Figure 4, $6)$.

Previous studies demonstrated that cationized antigen proteins, ED-OVA and recombinant OVA containing polyarginine, could induce high levels of immune responses ${ }^{[23,}$ ${ }^{29,30]}$. In comparison to $\mathrm{ED}_{7}-\mathrm{OVA}, \mathrm{ED}_{17}-\mathrm{OVA}$ with a higher degree of chemical modification, showed enhanced cellular uptake but inefficient antigen presentation (Figure 1f, g). This result was consistent with a previous report ${ }^{[23]}$, and suggests that extensive modification interferes with epitope recognition. In this study, ED7-OVA/CpG DNA hydrogel showed superior therapeutic efficacy to OVA/CpG DNA hydrogel (Figure 4), although no significant differences were detected between these groups in the IgG antibody levels (Figure 2b). The differences that were detected between ED7-OVA/CpG DNA hydrogel and OVA/CpG DNA hydrogel were the uptake and antigen presentation by antigen presenting cells (Figure 1f, g) 


\section{WILEY-VCH}

and the infiltration of leucocytes at the injection site (Figure 3c). Although the detailed mechanisms underlying the induction of antigen-specific immune responses after intratumoral injection remain to be elucidated, these differences observed could at least partly explain the higher activity of ED7-OVA/CpG DNA hydrogel in inhibiting tumor growth compared with OVA/CpG DNA hydrogel.

It was also demonstrated that cationized OVA derivatives showed no significant local tissue damage in vivo ${ }^{[23]}$. In this study, the proportion of mononuclear leucocytes infiltrating the injection site was different between the ED7-OVA/CpG DNA hydrogel-treated and the OVA/CFA-treated groups (Figure 3c). One of the components of CFA is mineral oil, which is slowly cleared from injection sites ${ }^{[32]}$. However, DNA hydrogel disappears from the injection site with a half-life of about $12 \mathrm{~h}^{[21]}$. DNA is quickly degraded by nucleases under in vivo conditions, and this degradation would be involved in the clearance of DNA hydrogel, even though the hydrogel formation significantly retarded the disappearance of DNA from the injection site ${ }^{[21]}$. Therefore, ease of degradation could be related to the condition of inflammation at the injection site. This would be attributed to the characteristics of phosphodiester DNA used for the preparation of CpG DNA hydrogel. In contrast to phosphorothioate-stabilized CpG DNA, which is the compound used in most studies using CpG DNA ${ }^{[9,33]}$, phosphodiester DNA is susceptible to nuclease degradation. This enzymatic instability could explain the few adverse side effects induced by the CpG DNA hydrogel, even though it contained many CpG sequences (92.5 nmol per injection). No apparent splenomegaly in mice immunized with ED7-OVA/CpG DNA hydrogel (Figure 3a) indicates that no substantially harmful systemic immune reactions were induced by this formulation. We also reported that the concentration of IL-6 in serum hardly increased after intradermal injection of OVA/CpG DNA hydrogel ${ }^{[21]}$. 


\section{WILEY-VCH}

Intratumoral injection was selected as the route of therapeutic immunization against EG7-OVA tumor-bearing mice. It is reported that direct injection of CpG ODN into tumors led to tumor regression by eliciting an antitumor $\mathrm{T}$ cell response ${ }^{[34,35]}$. CpG ODN also inhibits the suppressive function of myeloid derived suppressor cells in tumor bearing hosts ${ }^{\text {[36] }}$. A phase 1/2 study demonstrated that in situ vaccination of skin lesions of cutaneous T-cell lymphoma patients with CpG ODN simultaneously with localized regional radiation is feasible, which suggests that intratumoral injection of CpG ODN can be safely performed ${ }^{[37]}$. Furthermore, intratumoral peptide injection enhanced tumor cell antigenicity ${ }^{[2]}$. Therefore, the antitumor effects observed with intratumorally injected cationized antigen/CpG DNA hydrogel is consistent with previous studies.

Administration of R8-L2-pepI/CpG DNA hydrogel induced antigen specific tumor immunity more effectively than that of ED $7-\mathrm{OVA} / \mathrm{CpG}$ DNA hydrogel (Figure 6). This could be due to the higher number of epitopes in R8-L2-pepI compared with ED7-OVA when administered at a dose of $10 \mu \mathrm{g}$ /mouse. In addition, peptide based vaccines have superior properties to whole protein vaccines for several reasons. For example, peptides can be produced on a large scale by chemical synthesis without infectious materials, and quality control is possible through the use of techniques like liquid chromatography ${ }^{[38]}$. Furthermore, R8-L2-pepI and other cationic peptides can be obtained with high purity compared to chemically cationized antigen proteins, such as ED-OVAs. Thus, the use of peptides for cancer vaccination using cationized antigen could be an effective option for cancer therapy.

\section{Conclusion}

We have demonstrated that sustained release of antigen can be achieved through its cationization and intratumoral injection of cationized antigen incorporated into DNA hydrogel 


\section{WILEY-VCH}

induced antitumor immunity more effectively than unmodified antigen/DNA hydrogel. These findings have implications for optimal cancer immunotherapy based on CpG DNA hydrogel vaccination.

\section{Experimental Section}

Animals: Four-week-old ICR mice and six- to eight-week-old C57BL/6 mice were purchased from Japan SLC, Inc. (Shizuoka, Japan). TLR9 knockout (TLR9-/) mice with a C57BL/6 genetic background were purchased from Oriental Yeast Company (Tokyo, Japan). The protocols for animal experiments were approved by the Institutional Animal Experimentation Committee.

Cell culture: Mouse dendritic DC2.4 cells were kindly provided by Dr. K. L. Rock (University of Massachusetts Medical School, Worcester, MA, USA). They were cultured in RPMI1640 (Nissui Co., Ltd., Tokyo, Japan) supplemented with 10\% heat-inactivated FBS, 50 $\mu \mathrm{M}$ monothioglycerol, antibiotics, L-glutamine, and non-essential amino acids (Life Technologies, Gibco ${ }^{\circledR}$, USA). CD8OVA1.3, a mouse T cell hybridoma against an OVA class I epitope, was a generous gift from Dr. C. V. Harding (Case Western Reserve University, Cleveland, OH, USA). They were cultured in Dulbecco’s modified Eagle medium (DMEM; Nissui Pharmaceutical, Tokyo, Japan) supplemented with 10\% heat-inactivated FBS, $50 \mu \mathrm{M}$ monothioglycerol, antibiotics, and L-glutamine. EG7-OVA, an OVA transfectant of EL4, were purchased from American Type Culture Collection (Manassas, VA, USA). They were cultured in RPMI1640 supplemented with 10\% heat-inactivated FBS, $50 \mu \mathrm{M}$ monothioglycerol, antibiotics, and L-glutamine. Isolated mouse splenocytes were cultured in RPMI1640 supplemented with 10\% heat-inactivated FBS, $50 \mu \mathrm{M}$ monothioglycerol, antibiotics, and L-glutamine. The B16-BL6 murine melanoma cell line was obtained from the 


\section{WILEY-VCH}

Cancer Chemotherapy Center of the Japanese Foundation for Cancer Research, and cultured in DMEM supplemented with 10\% heat-inactivated FBS, antibiotics, and L-glutamine.

Cationization of OVA: OVA (albumin from chicken egg white, Sigma-Aldrich) was modified with ethylenediamine (ED, Wako Pure Chemical) using 1-(3-dimethylaminopropyl)-3carbodiimide (EDAC, Sigma-Aldrich) according to a previous report ${ }^{[39]}$. The degree of cationization was assessed by estimating the additional amino groups as measured by trinitrobenzenesulfonic acid (TNBS, Nacalai Tesque) ${ }^{[38]}$. The synthesis conditions and the physicochemical characteristics of OVA and ED-OVAs are summarized in Table 1.

Peptide: OVA class I epitopes, pepI (SIINFEKL), and R8-L2-pepI (RRRRRRRRFFRKSIINFEKL), were purchased from GenScript (Piscataway, NJ, USA). The HPLC purity of pepI and R8-L2-pepI was 96.9\% and 84.9\%, respectively. Fluorescein isothiocyanate isomer 1 (FITC)-pepI and FITC-R8-L2pepI, in which FITC was conjugated at the $\mathrm{N}$ terminal of the peptides, were also obtained from GenScript. The HPLC purity of FITCpepI and FITC-R8-L2-pepI was 91.8\% and 99.2\%, respectively.

Preparation of polypodna and DNA hydrogel: All phosphodiester ODNs were purchased from Integrated DNA Technologies, Inc. (Coralville, IA, USA). The sequences of the ODNs used are summarized in Table S3. Each hexapodna was prepared by mixing six equimolar ODNs as described previously ${ }^{[21]}$. DNA hydrogels were prepared by mixing equimolar amounts of two polypodna preparations in solution containing $150 \mathrm{mM}$ sodium chloride. GpC DNA hydrogel, which was prepared by replacing $\mathrm{CpG}$ sequences in the ODNs for the CpG DNA hydrogel with GpC sequences, was used as a non-immunostimulatory DNA hydrogel.

Complex formation of antigen with DNA: Antigen was incubated with GpC hexapodna-1 at different mixing ratios for $15 \mathrm{~min}$ at $37^{\circ} \mathrm{C}$. To confirm complex formation, the mixture was 


\section{WILEY-VCH}

subjected to electrophoresis using a $6 \%$ polyacrylamide gel at $200 \mathrm{~V}$ for $20 \mathrm{~min}$, and DNA was subsequently detected with ethidium bromide.

Release of antigen from DNA hydrogel: OVA and ED-OVAs were labeled with FITC (SigmaAldrich) to obtain FITC-OVA and FITC-ED-OVAs, respectively. The FITC labeled antigens were added to hexapodna solutions and a CpG DNA hydrogel was prepared by mixing the solutions. Release of FITC labeled antigen from DNA hydrogel was then examined as previously reported $^{[21]}$.

Antigen presentation assay: DNA $(10 \mu \mathrm{g} / \mathrm{ml})$, OVA or ED-OVA $(500 \mu \mathrm{g} / \mathrm{ml})$, and

CD8OVA1.3 cells were added to DC2.4 cells, the mixture was incubated for $24 \mathrm{~h}$ at $37^{\circ} \mathrm{C}$, and antigen presentation was examined as previously reported ${ }^{[21]}$.

Cellular uptake of antigen: DC2.4 cells $\left(1 \times 10^{5}\right.$ cells/well) on 48 -well culture plates were incubated with DNA $(10 \mu \mathrm{g} / \mathrm{ml})$ and OVA or ED-OVAs $(500 \mu \mathrm{g} / \mathrm{ml})$ for $2 \mathrm{~h}$ at $37^{\circ} \mathrm{C}$. The fluorescence intensity of the cells was then determined as previously reported ${ }^{[19]}$.

Disappearance of antigen from the injection site: Under isoflurane induced anesthesia, ICR mice were intradermally injected with $10 \mu \mathrm{g}$ of FITC-OVA or FITC-ED7-OVA in the presence or absence of $100 \mu \mathrm{g}$ of DNA hydrogel $(10 \mu \mathrm{l} / \mathrm{shot})$. At the indicated times after injection, mice were anesthetized and skin tissues including the injection site were excised, and homogenized to collect supernatant. The fluorescence intensity of the supernatant of the homogenates was subsequently measured.

Immunization of mice: Under isoflurane-induced anesthesia, C57BL/6 mice were injected with $10 \mu \mathrm{g}$ OVA or $\mathrm{ED}_{7}-\mathrm{OVA}$ into the dorsal skin in the presence or absence of $100 \mu \mathrm{g}$ DNA in $10 \mu \mathrm{l}$ of saline, or with $20 \mu \mathrm{l}$ of CFA. Mice were immunized three times on days 0,7 , and 


\section{WILEY-VCH}

14. Seven days after the last immunization, mice were euthanized with isoflurane, and serum and spleen were collected. Serum samples were stored at $-80^{\circ} \mathrm{C}$ until measurement.

Measurement of OVA-specific antibody: Serum samples were serially diluted to measure the OVA-specific total IgG levels by ELISA as previously described ${ }^{[21]}$.

IFN- $\gamma$ secretion from spleen cells: Seven days after the last immunization, spleen cells were isolated, purified, and cultured in the presence of OVA $(1 \mathrm{mg} / \mathrm{ml})$ in 48 -well culture plated for 4 days. The concentration of IFN- $\gamma$ in supernatant of the isolated spleen cells was measured as previously described ${ }^{[21]}$.

Measurement of spleen weight: Spleen was collected from different sets of C57BL/6 mice seven days after the third immunization at weekly intervals. Spleen weight was measured and large spleens were an indicator of splenomegaly, a systemic adverse effect of immunostimulatory compounds.

Hematoxylin and eosin staining of skin sections: Under isoflurane induced anesthesia, the dorsal skin of C57BL/6 mice was injected with $10 \mu \mathrm{g}$ OVA or ED7-OVA and $100 \mu \mathrm{g}$ DNA or CFA. Mice were immunized three times on days 0,7 , and 14. Seven days after the last immunization, the injection site was excised, fixed in 4\% paraformaldehyde, embedded in paraffin, sliced and stained with hematoxylin and eosin. Stained samples were examined under a microscope for histological evaluation.

Treatment of tumor-bearing mice: C57BL/6 mice were inoculated intradermally with EG7OVA cells ( $5 \times 10^{6}$ cells/mouse). When the tumor volume exceeded $200 \mathrm{~mm}^{3}, 100 \mu \mathrm{g}$ of DNA and $10 \mu \mathrm{g}$ of OVA, ED 7 -OVA, R8-L2-pepI, or $3.45 \mu \mathrm{g}$ of pepI in a volume of $10 \mu \mathrm{l}$ was injected directly into the tumor. The intratumoral injection was repeated three times at 5-day 


\section{WILEY-VCH}

intervals. The tumor size was measured with a slide caliper, and tumor volume was calculated using the following formula: tumor volume $\left(\mathrm{mm}^{3}\right)=0.5 \times$ length $(\mathrm{mm}) \times[\text { width }(\mathrm{mm})]^{2}$.

Dynamic light scattering analysis: The apparent size of the antigen and hexapodna mixture was determined by the dynamic light scattering (DLS) method using a Malvern Zetasizer 3000HS (Malvern Instruments, Malvern, UK) at $20^{\circ} \mathrm{C}$.

Statistical analysis: Statistical analyses were performed using Statcel3 (OMS Publishing, Saitama, Japan). Statistical differences were analyzed using one-way analysis of variance (ANOVA) followed by the Turkey-Kramer multiple comparison test. To analyze the antitumor effect, Kaplan-Meier survival curves were generated, and log-rank tests were performed. $P$ values of $<0.05$ were considered significant.

\section{Supporting Information}

Supporting Information is available from the Wiley Online Library or from the author.

\section{Acknowledgements}

This work was supported in part by Grants-in-Aid for Scientific Research (B) (23390010, 26293008) from Japan Society for the Promotion of Science (JSPS), by a Grant-in-Aid for Scientific Research on Innovative Areas “Carcinogenic spiral” (25114706) from the Ministry of Education, Culture, Sports, Science and Technology of Japan, and by Uehara Memorial Foundation.

Received: ((will be filled in by the editorial staff))

Revised: ((will be filled in by the editorial staff)) Published online: ((will be filled in by the editorial staff)) 


\section{WILEY-VCH}

[1] JM. Kirkwood, LH. Butterfield, AA. Tarhini, H. Zarour, P. Kalinski, S. Ferrone, CaCancer J. Clin. 2012, 62, 309.

[2] D. Nobuoka, T. Yoshikawa, M. Takahashi, T. Iwata, K. Horie, M. Shimomura, S. Suzuki, N. Sakemura, M. Nakatsugawa, H. Sadamori, T. Yagi, T. Fujiwara, T. Nakatsura, Cancer Immunol. Immunother. 2013, 62, 639.

[3] A. Batista-Duharte, EB. Lindblad, E. Oviedo-Orta, Toxicol. Lett. 2011, 203, 97.

[4] DT. O’Hagan, E. De. Gregorio, Drug Discovery Today 2009, 14, 541.

[5] A. Singh, NA. Peppas, Adv. Mater. 2014, 26, 6530.

[6] JM. Silva, M. Videira, R. Gaspar, V. Preat, H. Florindo, J. Controlled Release, 2013, 168, 179.

[7] Y. Wen, JH. Collier, Curr. Opin. Immunol. 2015, 35, 73.

[8] M, Roman, E. Martin-Orozco, JS. Goodman, MD. Nguyen, Y. Sato, A. Ronaghy, RS. Kornbluth, DD. Richman, DA. Carson, E. Raz, Nat. Med. (N. Y., NY, U. S.) 1997, 3, 849.

[9] DM. Klinman, Nat. Rev. Immunol. 2004, 4, 249.

[10] AM. Krieg, Nat. Rev. Drug Discovery 2006, 5, 471.

[11] H.Wagner, Curr. Opin. Microbiol. 2002, 5, 62.

[12] EJ. Hennessy, AE. Parker, LA. O'Neill, Nat. Rev. Drug Discovery 2010, 9, 293.

[13] J. Karbach, A. Neumann, C. Wahle, K. Brand, S. Gnjatic, E. Jäger, Cancer Res. 2012, 72, 4304. 


\section{WILEY-VCH}

[14] C. Maisonneuve, S. Bertholet, E. De Gregorio, Proc. Natl. Acad. Sci. U. S. A. 2014, 111, 12294.

[15] UM. Sarmiento, JR. Perez, JM. Becker, R. Narayanan, Antisense Res. Dev. 1994, 4, 99.

[16] K. Kapp, C. Kleuss, M. Schroff, B. Wittig, Mol. Ther. --Nucleic Acids 2014, 3, e170.

[17] K. Mohri, N. Takahashi, M. Nishikawa, E. Kusuki, T. Shiomi, Y. Takahashi, Y. Takakura, J. Controlled Release 2012, 163, 285.

[18] M. Nishikawa, M. Matono, S. Rattanakiat, N. Matsuoka, Y. Takakura, Immunology 2008, 124, 247.

[19] K. Mohri, M. Nishikawa, N. Takahashi, T. Shiomi, N. Matsuoka, K. Ogawa, M. Endo, K. Hidaka, H. Sugiyama, Y. Takahashi, Y. Takakura, ACS Nano 2012, 6, 5931.

[20] S. Uno, M. Nishikawa, K. Mohri, Y. Umeki, N. Matsuzaki, Y. Takahashi, H. Fujita, N. Kadowaki, Y. Takakura, Nanomedicine (N. Y., NY, U. S.) 2013, 10, 765.

[21] M. Nishikawa, K. Ogawa, Y. Umeki, K. Mohri, Y. Kawasaki, H. Watanabe, N. Takahashi, E. Kusuki, R. Takahashi, Y. Takahashi, Y. Takakura, J. Controlled Release 2014, 180, 25.

[22] MC. Chen, SF. Huang, KY. Lai, MH. Ling, Biomaterials 2013, 34, 3077.

[23] T. Ikenaga, Y. Yamasaki , K. Shakushiro, M. Nishikawa, Y. Takakura, Vaccine 2004, 22, 2609.

[24] JB. Flechtner, KP. Cohane, S. Mehta, P. Slusarewicz, AK. Leonard, BH. Barber, DL. Levey, S. Andjelic, J. Immunol. 2006, 177, 1017. 


\section{WILEY-VCH}

[25] AT. Glenny, GAH. Buttle, MF. Stevens, J. Pathol. Bacteriol. 1931, 34, 267.

[26] SG. Reed, S. Bertholet, RN. Coler, M. Friede, Trends Immunol. 2009, 30, 23.

[27] CC. Lin, AT. Metters, Adv. Drug Delivery Rev. 2006, 58, 1379.

[28] KH. Bae, LS. Wang, M. Kurisawa, J. Mater. Chem. B 2013, 1, 5371.

[29] RJ. Apple, PL. Domen, A. Muckerheide, JG. Michael, J. Immunol. 1988, 140, 3290.

[30] H. Mitsui, T. Okamoto, M. Kanzaki, T. Inozume, N. Shibagaki, S. Shimada. Br. J. Dermatol. 2010, 162, 29.

[31] T. Yoshikawa, N. Okada, A. Oda, K. Matsuo, K. Matsuo, Y. Mukai, Y. Yoshida, T.Akagi, M. Akashi, S. Nakagawa, Biochem. Biophys. Res. Commun. 2008, 366, 408.

[32] RK. Gupta, EH. Relyveld, EB. Lindblad, B. Bizzini, S. Ben-Efraim, CK. Gupta, Vaccine 1993, 11, 293.

[33] A. de Titta, M. Ballester, Z. Julier, C. Nembrini, L. Jeanbart, AJ. Van der Vlies, MA. Swartz, JA. Hubbell, Proc. Natl. Acad. Sci. U. S. A. 2013, 110, 19902.

[34] AS. Lonsdorf, H. Kuekrek, BV. Stem, BO. Boehm, PV. Lehmann, M. Tary-Lehmann, J. Immunol. 2003, 171, 3941.

[35] Y. Shirota, H. Shirota, DM. Klinman, J. Immunol. 2012, 188, 1592.

[36] C. Zoglmeier , H. Bauer , D. Nörenberg, G. Wedekind, P. Bittner , N. Sandholzer , M. Rapp , D. Anz , S. Endres , C. Bourquin, Clin. Cancer Res. 2011, 17, 1765. 
[37] YH. Kim, D. Gratzinger, C. Harrison, JD. Brody, DK. Czerwinski, WZ. Ai, A. Morales, F. Abdulla, L. Xing, D. Navi, RJ. Tibshirani, RH. Advani, B. Lingala, S. Shah, RT. Hoppe, R. Levy, Blood 2012, 119, 355.

[38] AW. Purcell, J. McCluskey, J. Rossjohn. Nat. Rev. Drug Discovery 2007, 6, 404.

[39] AF. Habeeb, Anal. Biochem. 1966, 14, 328. 


\section{WILEY-VCH}

Immunostimulatory DNA hydrogel-based sustained release system using cationized antigen which can electrostatically interact with DNA is developed, and this system can induce antigen-specific immune responses, which leads to effective inhibition of antigenpositive tumor growth in mice. This study provides experimental evidence for future clinical application of this system to induce potent antitumor immunity.

Keyword : Drug Delivery

Yuka Umeki, Kohta Mohri, Yohji Kawasaki, Hiroshi Watanabe, Rei Takahashi, Yuki Takahashi, Yoshinobu Takakura, and Makiya Nishikawa*

Induction of Potent Antitumor Immunity by Sustained Release of Cationic Antigen from a DNA-based Hydrogel with Adjuvant Activity

ToC figure ((Please choose one size: $55 \mathrm{~mm}$ broad $\times 50 \mathrm{~mm}$ high or $110 \mathrm{~mm}$ broad $\times 20 \mathrm{~mm}$ high. Please do not use any other dimensions))

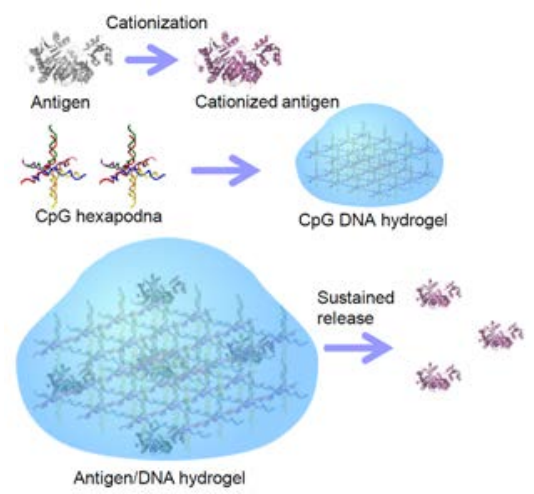

